\title{
WPS2594
}

\section{Committing to Civil Service Reform: The Performance of Pre-Shipment Inspection under Different Institutional Regimes}

Noel Johnson *

\footnotetext{
* Washington University at St. Louis, Economics Department, 205 Eliot Hall, Campus Box 1208, St. Louis, MO 63130-4899, johnson@wueconc.wustl.edu. This project was undertaken while I was a summer intern at the World Bank. I would like to thank, above all, Luca Barbone for suggesting this project and providing support throughout the development of the project. I would also like to thank the following people for reading drafts and providing additional guidance: Luis-Alvaro Sanchez, Philip Keefer, Shantayanan Devarajan, Cyril Muller, Douglass North and the members of the economic history group at Washington University, Paul Rothstein, Courtney LaFountain, and Alexandra Mislin. Of course, any mistakes are my own.
} 
Typically a developing country's customs service accounts for both a large percentage of its revenues and an even larger percentage of its corruption. Among development agencies, one of the more popular prescriptions to address corruption in customs, and evasion by importers more generally, has been the outsourcing of certain functions once undertaken by customs officers to Pre-shipment Inspection (PSI) companies. These companies are typically employed to provide information on the taxable value of imports coming into a country. In principle, one of the primary purposes of PSI is the deterrence of both corruption and evasion. In practice, however, there are some serious questions about the true effectiveness of PSI in carrying out these missions.

The success of individual PSI contracts is highly dependant upon the existing institutional environment. By institutions we mean the formal and informal rules of the game along with their enforcement characteristics which determine the incentives of individual agents. However, how individual agents such as Importers, the Customs Service, or the Ministry of Finance will respond to the introduction of a PSI contract given existing institutions has never been explicitly investigated. This paper is an attempt to provide a theoretical background which explicitly allows the institutional environment in which PSI is introduced to play a role in its success in deterring corruption and evasion. As such, factors such as the compensation of Customs officials, their physical control of the borders, and the ability of the Ministry of Finance to implement complementary reforms to the PSI contract will play a role. It will be shown that the performance of a PSI program will, more often than not, require both tailoring the PSI contract to existing institutions and, sometimes, altering existing institutions to be more conducive to PSI. Whether or not the costs of such tailoring are less than the benefits brought by PSI will remain an open question.

The first section of the paper will give some background on what PSI is, where it is used, and what has been its impact. Section two will introduce a principal-agent model to illustrate the major incentive and credibility issues surrounding the use of PSI. Section three will use the model to formulate policy prescriptions concerning under what institutional settings a PSI contract should be chosen and how this contract should be structured so as to minimize the transaction costs associated with its implementation. Section four will conclude.

\section{Section 1: The Organization of Pre-shipment Inspection Services}

Collecting customs revenues in developing countries is costly in no small part due to the prevalence of corruption on the part of both customs agents and tax payers. One of the more controversial attempts supported by bilateral donor agencies has been the introduction of Pre-Shipment Inspection (PSI) contracts under certain circumstances. We define corruption as collusion between an Importer and a Customs Agent with the purpose to defraud the government. This is as opposed to evasion, which we define as the attempt by the Importer, in isolation, to avoid paying taxes. There can be evasion without corruption, however, the opposite is not true. 
The predominant source of corruption in customs collection in the developing world is no great mystery. Developing countries, as a group, tend to have higher marginal tax rates on imports and collect a greater percentage of overall tax revenue through customs. High rates lead to large rent-seeking opportunities for both Customs Agents and Importers. ${ }^{1} \quad$ Since lowering tax rates is often politically infeasible or fiscally imprudent (in the absence of other sources of government revenue), it is necessary, at least in the short-run, to find ways of overcoming corruption given the existing tax system. In lieu of overhauling tax-rates, PSI is often suggested as a low-cost second-best solution.

A PSI contract entails the hiring of a private company to inspect goods destined to be imported at their point of embarkation. Originally, PSI was primarily limited to the detection of over-invoicing so as to reduce capital flight . At present, however, PSI is mostly used to detect revenue fraud by verifying the price of goods to be imported, their classification, and to detect outright deceit on customs declarations. There are several seemingly good reasons to advocate its use for these purposes. Normally, given their geographical separation, there is little contact between customs authorities and PSI agents, thereby making collusion between them extremely costly. Also, in a competitive environment, the PSI company is highly dependent upon maintaining a good reputation and, therefore, has strong incentives to avoid corrupt activities (such as colluding with the importer or government officials). ${ }^{2}$

Typically, a PSI contract works as follows: The Importer is required to notify the local PSI office in the country of origin that he wishes to bring in a shipment. PSI employees then inspect the shipment with the goal of either verifying its contents against the Importer's invoice, or, in the case of discrepancies, of "up-lifting" the taxable value of the goods on the Invoice. Once the PSI company is satisfied with any changes made to the Invoice, they seal the shipment and a "Clean Report of Findings" (CRF) is sent to the country of destination ahead of the shipment. The CRF specifies the value and categorization of the goods as determined by the PSI employees. It is typically sent to the Customs Service at the point of destination and, sometimes, to the destination country Ministry of Finance as well.

The Customs Service is required to collect revenues on imported goods. ${ }^{3}$ The data coming from PSI is meant to reduce the costs of deterrence of corruption and evasion

\footnotetext{
${ }^{1}$ Burgess and Stern estimate that customs revenues compose approximately $2.74 \%$ of tax revenues in industrial countries, but, $28.39 \%$ in Africa and $30.9 \%$ in Asia. They also note that these numbers may underestimate the amount of revenues collected by customs officials since oftentimes excise taxes are also collected on the border. See Robin Burgess and Nicholas Stern, "Taxation and Development," Journal of Economic Literature, Vol. XXXI, (June, 1993).

${ }^{2}$ The largest PSI company in operation today is the Swiss Société Générale de Surveillance, however, there are several other competitive PSI companies in operation around the world (see Table 1 below).

${ }^{3}$ However, there is one example of the actual collection duties of customs being taken over for a time by a PSI company in the Philippines (See Section 3).
} 
in two ways. First, the information provided by the PSI company is meant to assist Customs Collectors tasked with collecting revenues to overcome the transaction costs associated with weeding out evasion by the Importer. Secondly, this data is meant to assist the Ministry of Finance in identifying where corruption is taking place within Customs so that it can be rooted out. Typically, the Ministry of Finance in a developing country will receive a lump-sum from Customs every so often for the amount of revenues collected (not a check for taxes collected on every shipment). If the Ministry of Finance attempts to match this lump-sum up with the data provided to them by the PSI company, it may tell them that corruption exists (because the PSI figures are higher than the check received from Customs), however, it will not tell them where corruption exists. Thus, in order for PSI to be successful in deterring corruption within Customs, the data provided by PSI must be combined with that from Customs Collectors in an "ex-post reconciliation" which will reveal any discrepancies between the two. It follows, that the incentives of Customs Agents, who are in a position to carry out a successful ex-post reconciliation, are absolutely vital to whether or PSI will succeed.

Fundamentally, then, PSI is designed to overcome two sorts of information asymmetries: that between the average developing country ministry of finance and its Customs Agents (who may be accepting bribes from Importers and, thus, be unwilling to turn themselves in by engaging in ex-post reconciliation) and that between the Customs Agents and the Importer. Thus, what a PSI company is actually being paid for, is accurate, shipment level, data on the value of imports. If the Ministry of Finance in the importing country is serious about customs reform ${ }^{4}$ and it is paying a PSI company between three and four percent of the value of imports to create valuable information, it will be in its incentives to use that information. However, in order to undertake an expost reconciliation, the information from the PSI company must be matched with that going to Customs Agents. It is not at all clear that customs will be willing to supply this information, especially if they are the source of the corruption that the PSI contract was implemented to address in the first place. Thus, if there is no expectation that Customs Agents will participate in ex-post reconciliation, there will also be no incentive for the Ministry of Finance to use PSI in the first place. This would make it pyrrhic for an International Aid Agency to require the use of PSI since it would only add costs to the collection process. It is absolutely vital, when inquiring as to the usefulness of PSI in a particular situation, to have some idea as to whether or not the incentives of Customs Agents, the Ministry of Finance, and the Importer, align in such a way that the contract will be respected.

Simply inspecting the existing evidence for the success of PSI in different circumstances offers little guidance as to when it should be implemented. The use of PSI to combat corruption and evasion has experienced very inconsistent success in widely different institutional settings. Oftentimes, fundamentally identical PSI contracts have

\footnotetext{
${ }^{4}$ Which we will assume it is throughout this paper. If the ministry of finance is corrupt, then credible civil service reform is virtually impossible and our analysis would be trivial.
} 
been used in countries with different institutions with drastically different results. A list of currently active PSI contracts is given in Table $1 .^{5}$

Table 1

\begin{tabular}{|c|c|c|}
\hline Country & $\begin{array}{c}\begin{array}{c}\text { Objective of } \\
\text { Contract }\end{array} \\
\end{array}$ & Participating PSI Companies \\
\hline Angola & Forex/Customs & "SGS, BIVAC, Control Union, ITS \\
\hline Argentina & Customs & Inspectorate, SGS \\
\hline Bangladesh & Customs & BIVAC, ITS, Inspectorate \\
\hline Benin & Forex/Customs & BIVAC \\
\hline Bolivia & Customs & Inspectorate, SGS \\
\hline Burkina Faso & Customs & SGS \\
\hline Burundi & Forex & SGS \\
\hline Cameroon & Customs & SGS \\
\hline Central African Republic & Customs & SGS \\
\hline Comoros & Forex/Customs & COTECNA \\
\hline Congo & Customs & BIVAC \\
\hline Côte D'Ivoire & Customs & SGS \\
\hline Dem. Republic of Congo & Customs & SGS \\
\hline Ecuador & Customs & BIVAC, COTECNA, ITS, SGS \\
\hline Ethiopia & Forex/Customs & SGS \\
\hline Gambia & Customs & BIVAC \\
\hline Georgia & Customs & ITS \\
\hline Ghana & Forex/Customs & BIVAC, COTECNA, ITS, SGS \\
\hline Guinea & Customs & SGS, BIVAC, COTECNA \\
\hline Iran & Quality/Quantity & Inspectorate, ITS, OMIC, SGS \\
\hline Kenya & Customs & BIVAC, COTECNA, SGS \\
\hline Liberia & Customs & BIVAC \\
\hline Madagascar & Forex/Customs & BIVAC \\
\hline Malawi & Customs & SGS \\
\hline Mauritania & Customs & SGS \\
\hline Mali & Forex/Customs & SGS \\
\hline Mexico & Customs & BIVAC, ITS, SGS \\
\hline Mozambique & Forex/Customs & ITS \\
\hline Niger & Forex/Customs & COTECNA \\
\hline Nigeria & Forex/Customs & BIVAC, COTECNA, ITS, SGS \\
\hline Peru & Customs & BIVAC, COTECNA, SGS \\
\hline Rwanda & Customs & SGS \\
\hline Senegal & Customs & BIVAC, SGS \\
\hline Sierra Leone & Customs & BIVAC \\
\hline Tanzania & Customs & COTECNA \\
\hline Togo & Forex/Customs & COTECNA \\
\hline Uganda & Customs & ITS \\
\hline Uzbekistan & Forex & ITS \\
\hline Zanzibar & Forex & SGS \\
\hline
\end{tabular}

A cursory inspection of several of the contracts represented in the Table demonstrates the large amount of variability in success of PSI contracts. PSI can be very effective and there have been several notable cases in which the introduction of PSI has significantly contributed to an increase in tax revenues. One of the most well known success stories, the Philippines, introduced PSI in 1987 with a goal of increasing

${ }^{5}$ Source: Unpublished lecture by Cyril Muller given at the World Bank, Summer 2000. 
revenues. Along with the introduction of the PSI contract, they also significantly reformed their entire customs bureaucracy. Between March 1992 and March 2000 there were $\$ 11.6$ billion of uplifts ${ }^{6}$ recorded which led to increased collections of $\$ 27$ billion compared with fees for the PSI company totaling some $\$ 9$ billion. ${ }^{7}$ Other success stories include Mexico and Argentina. However, in all three of the above cases, the introduction of the PSI contract was accompanied by far-reaching reforms in the organization of Customs. Thus, in Mexico between 1989 and 1992 the customs service was reduced from 8,800 personnel to 4,100 (3,000 of which were new recruits). ${ }^{8}$ In the Philippines, the contract with the PSI company actually arranged things so that ex-post reconciliation and payment of customs duties were handled directly by the PSI company, thereby bypassing Customs altogether. ${ }^{9}$

Alongside of these success stories, however, there are just as many, if not more examples where PSI has unambiguously failed to make any significant impact in combating corruption and evasion. As Patrick Low notes in his seminal work on the issue, there is often a large gap between "adjustments" reported by PSI companies and actual effects on revenue collected in the importing country. ${ }^{10}$ One possible explanation of these failures is that the information provided by the PSI company simply isn't being used to good effect by the Customs Service or the Ministry of Finance. Thus, in Zambia Low found that there was about a $46 \%$ shortfall between the PSI reported value of potential customs revenue and the actual value of taxes collected. In both Tanzania and Mali Low found the shortfalls of around 50\%. In all three cases, for one reason or another, Importers were able to collude with Customs Agents in order to avoid having to pay taxes on the value of imports reported by the PSI company.

In addition to outright corruption in Customs undermining the incentives to engage in ex-post reconciliation, a second possible explanation for the failure of PSI in certain cases is the extent to which Customs is actually in physical control of their borders. Mozambique, for example, has employed the service of a PSI company since 1990. However, there is very little evidence that Customs uses the information provided them by the CRF when collecting on individual imports, let alone to engage in ex-post reconciliation. ${ }^{11}$ The fact that it is very easy to smuggle consignments across the borders of Mozambique, rather than going through Customs and the PSI company means that,

\footnotetext{
${ }^{6}$ An "uplift" occurs when the PSI company increases the value of imports as declared by the importer on its Report of Findings. An uplift is not the same thing as an increase in tax revenues collected.

${ }^{7}$ Unpublished lecture given by Cyril Muller at the World Bank, Summer 2000.

${ }^{8}$ Low, 117.

${ }^{9}$ Low, 112 .

${ }^{10}$ Patrick Low. Preshipment Inspection Services, World Bank Discussion Papers (278), 1995.

11 "Mozambique: Impediments to Industrial Sector Recovery," World Bank Report no. 13572-MOZ, (1995), p.21.
} 
even if the information from the PSI company were used and Customs officers were able to more easily identify evaders, the effect of this would be to simply discourage Importers from going through Customs in the first place. Any discussion of PSI should take this possibility of smuggling into account.

Given the widely differing institutional structures surrounding the introduction of PSI in these countries, it would be extremely difficult to do good empirical work comparing the performance of different PSI contracts across countries without some model to guide us. While there have been no attempts to do this in the literature there does seem to be something of a consensus concerning under what conditions PSI should be used and what should be required from the parties to the PSI contract.

The first widely held belief is that PSI should be used in countries with "weak" institutions where comprehensive customs reform would be too costly. It is not entirely clear what is meant by most authors when they refer to "weak" institutions. Thus, for example, a paper prepared by the Latin American Economic Research Foundation on PSI notes that, "Experience and literature on the subject [PSI] advices [sic] the introduction of PSI mechanisms for countries that have a poor Customs performance (in general, countries of relatively lower development)." ${ }^{\prime 2}$ One of the benefits of developing a model in Section 2 will be that it will allow us to be more specific about what might be meant by "weak" institutions.

In addition to the belief that PSI should be used in countries with weak institutions that are unable to engage in more comprehensive reforms, several studies have also identified what they consider to be the "proximate" causes for the performance of PSI. ${ }^{13}$ In particular, Patrick Low singles out at least three conditions which must obtain for the success of PSI related reform. First, and most importantly, that an ex-post reconciliation should be carried out. Second, that the PSI company should send a copy of the Report of Findings to both the Ministry of Finance and the Customs Agency. Third, that there should be a judicial mechanism for complaints against PSI companies and Customs Agencies by the Importer. To these three conditions should probably be added a fourth, that in order for there to be any chance of success, the customs service must have some measure of physical control over their customs territory.

There is a deeper question, however, above and beyond that of proximate causes. In particular, given the difficulties in identifying, empirically, what the effect of PSI is on

\footnotetext{
${ }^{12}$ Latin American Economic Research Foundation, "Customs Control in an Open Economy: The Case on the Preshipment Inspection Program in Argentina," (1999), p.22.

${ }^{13}$ Although, it is worth noting that there is hardly ever explicit mention of what type of reforms accompany the introduction of a PSI contract. Discussion is usually limited to the PSI contract itself (e.g. "Great emphasis was placed in the contract on ex-post reconciliation"). One of the points of this paper will hopefully be to shift more emphasis towards concentrating on the reforms which accompany the PSI contract (and interact with it) but which don't necessarily have to do directly with the PSI company or the information which comes from the PSI company (i.e. how are customs agents compensated, what are the incentives of importers given a certain level of punishment).
} 
corruption and evasion, we need to know what sort of factors contribute to those conditions discussed above being present or not. Of the four suggestions, it's undoubtedly the first, successfully implementing ex-post reconciliation, which is the most difficult to ensure and the most important for success. It has been suggested by Mark Dutz in a recent note on PSI, that there is a broad consensus that unless governments consistently use ex-post reconciliation and act on the information it generates, there is little hope for PSI to be useful in combating corruption and evasion. ${ }^{14}$ However, the fundamental question is, not whether or not ex-post reconciliation is important. It obviously is. Rather, what reformers need to know is how does one ensure that an expost reconciliation is carried out? Previous authors, such as Low, have implied that simply introducing a PSI contract may serve to eliminate the information asymmetries between the government and customs. ${ }^{15}$ Simply altering the formal rules of the game by requiring PSI and ex-post reconciliation may work in a situation in which third-party enforcement of contracts is reliable. However, it is a well known fact that many developing country Customs Agencies are highly independent of other braches of government, making it extremely difficult for the Ministry of Finance to "require" anything. What we need to ask is, how should the government go about ensuring that PSI will work given that they cannot simply force Customs to comply with a PSI contract and given the existing institutional framework (or, alternatively, should a PSI contract be used at all). Simply introducing a PSI contract into a situation will often do nothing if the incentives of Customs Agents do not align with those of the Ministry of Finance. Unless incentives are credibly changed so that parties to a PSI contract benefit by those actions which support ex-post reconciliation, either it won't take place, or, it will be prohibitively costly to enforce.

Thus, there are two basic conclusions from the literature on PSI which must be addressed. The first is that PSI should be used in countries with weak institutions, and the second is that in order for PSI to work there must be a successful ex-post reconciliation. Whether or not these two requirements are compatible is an open issue. In the next section, I develop a model to investigate under what institutional conditions successful ex-post reconciliation will be possible.

\section{Section 2: The Model}

We can model the PSI relationship using the tools of the New Institutional Economics. ${ }^{16}$ We define Institutions to be the formal and informal rules of the game along with their enforcement characteristics. Thus, requiring Customs Agents to engage in ex-post reconciliation in a PSI contract is an example of a formal rule. Likewise, the levels of punishments and rewards associated with corruption, evasion, or, honesty are

\footnotetext{
${ }^{14}$ Mark Dutz, "Observations on the Use and Usefulness of Pre-Shipment Inspection (PSI) Services."

${ }^{15}$ Low, xvii.

${ }^{16}$ The following is based on Douglass North. Institutions, Institutional Change, and Economic Performance, (Cambridge, CUP: 1990).
} 
part of the Institutional structure. We define an Organization as a group of purposeful actors whose actions are determined by the interaction of the Institutional structure and technology. The Organizations in our model will be the Customs Agency, the Ministry of Finance, and the Importer. Institutions may be thought of as mechanisms developed by society to reduce the transaction costs of engaging in economic exchange. In our model, the relevant transaction costs to consider are the informational asymmetries which exist between Customs and the Importer who may be evading and between the Ministry of Finance and the Customs Agents who may be corrupt. A PSI contract may be thought of as a change in the formal rules of the game by the Ministry of Finance designed to reduce these transaction costs. One of the most important results from NIE is that simply altering one or more of the formal rules of the game without considering the broader institutional context in which the changes are taking place will often lead to that rule either being ignored or having unintended consequences. ${ }^{17}$ Thus, we would like a model which tells us something about the institutional conditions under which PSI will work (as indicated by a successful ex-post reconciliation) and how the PSI contract should be designed so that it fits with the existing Institutional and Organizational structure.

To answer these questions we must be more specific about the objectives of the actors in our model and what their choices are as opposed to what is taken as given. ${ }^{18}$ The three actors we explicitly consider are the Ministry of Finance, Customs, and the Importer. The Importer brings in goods which have an after-tax value of $V_{n e}$ if he chooses not to evade taxes and $V_{e}$ if taxes are evaded. The Ministry of Finance collects tax revenues on imports which are worth $t_{n e}$ if there is no evasion and $t_{e}$ if there is. We define $\Delta V \equiv V_{e}-V_{n e}$ and $\Delta t \equiv t_{n e}-t_{e}$, and it is assumed that $\Delta t \geq \Delta V \geq 0$ so that, in the absence of transaction costs, it is not profitable for the Importer to bribe the Ministry of Finance. ${ }^{19}$ Since it is costly for the Ministry of Finance to monitor the behavior of the Importer, it sub-contracts with a Customs Manager who can do it more cheaply. They pay the Customs Manager a wage of $W$ to monitor the Importer and collect tax revenues. The cost faced by Customs for monitoring each shipment is fixed at $c_{m}$. It catches evasion with a probability $\gamma \in[0,1]$ and, if it succeeds in identifying evasion, it must decide whether or not to report it to the Ministry of Finance. Since Customs Agents are self-interested income maximizers it is possible for them to collude with the Importer to defraud the government. If they report discovered evasion, then the Importer is fined $P_{e}^{I}>\Delta V$ and Customs receives a reward of $r$. Without loss of generality, we can normalize $W-c_{m}$, the net wage of Customs, to be equal to zero. To counter the

\footnotetext{
${ }^{17}$ For example, consider what happened in the Former Soviet Union when reformers instituted western style formal rules governing economic exchange to find that this only served to reinforce existing, and deeply embedded, inegalitarian and inefficient informal rules of exchange.

${ }^{18}$ The principal-agent model which follows is loosely based on that presented by Gunnar S. Eskelund and Henrik Thiele, "Corruption under Moral Hazard," World Bank Policy Research Paper 2204, (1999).

${ }^{19}$ That is, we preclude the possibility of any Coasian side-bargains between the Importer and the Ministry of Finance.
} 
possibility of collusion between Customs Agents and the Importer, the Ministry of Finance engages in audits of Customs which succeed with probability $\pi \in[0,1]$. If successful, the audit reveals collusion only, it will not detect evasion on the part of the Importer. ${ }^{20}$ If collusion is detected, then Customs must pay a fine of $P_{a}^{C}$ and the Importer must pay $P_{a}^{I}>\Delta V$.

We also allow Customs Agents to be compensated with "share pay". The amount of share pay is characterized by a variable, $h \in[0,1]$ which is the percentage of tax revenues accruing to the Customs Agent out of tax revenues received by the Ministry of Finance. If $h$ were equal to one then the Customs Agent would, in effect, be a tax farmer and typically would be receiving a negative wage representing the up-front payment made to the Ministry of Finance in exchange for the rights to collect customs revenues. We ignore the size of the up-front payment and concentrate instead on the incentive effects that altering the size of share pay has on the likelihood that ex-post reconciliation will be carried out. $^{21}$

Collusion will be profitable for both Customs and the Importer so long as:

$$
r+h \Delta t \leq P_{e}^{I}-\pi\left(P_{a}^{I}+P_{a}^{C}\right)
$$

Equation (1) states that the benefit to the Customs Agent from his reward are less than the benefit to the Importer from avoiding the penalty on evasion minus the expected cost of detection borne by both the Ministry of Finance and the Customs Agent. If equation (1) holds, and the Importer is caught trying to evade, then the Importer will pay Customs a bribe equal to:

$$
b=k\left[P_{e}^{I}-r-h \Delta t-\pi\left(P_{a}^{I}+P_{a}^{C}\right)\right]+r+\pi P_{a}^{C}+h \Delta t
$$

Where $k \in[0,1]$ is a measure of the bargaining power of Customs. $k=1$ implies that Customs Agents can extract all of the surplus from collusion with the Importer.

The values of $r, P_{e}^{I}, P_{a}^{I}, P_{a}^{C}, \gamma, h, \pi, \Delta V$, and $\Delta t$ are determined exogenously in the model. ${ }^{22}$ Given the values of these exogenous variables, the Ministry of Finance will

\footnotetext{
${ }^{20}$ Of course, it is assumed that if corruption is detected, then evasion has already been discovered. What this requirement eliminates is the possibility of audits detecting evasion where monitoring by customs has already failed.

${ }^{21}$ However, one way to avoid this problem would be to assume that the share contract between the Ministry of Finance and the Customs Agents is auctioned off competitively resulting in all rentes being expropriated by Customs ex ante.

${ }^{22}$ There are many issues concerning credible ceilings on the values of the reward and penalties which we will not discuss.
} 
choose whether or not to implement a PSI contract at a cost of $c_{p}$. We assume that if PSI is used, then in the contract the PSI company is required to send a copy of the Report of Findings to the Ministry of Finance (or some independent body which it creates) and Customs. If a contract is not implemented then the Importer chooses whether or not to evade. If a contract is implemented, then Customs makes a decision as to whether or not to use the information provided by the PSI company by supporting an ex-post reconciliation. If Customs provides the information ${ }^{23}$, then the probability of a successful audit of Customs by the Ministry of Finance becomes $\pi=1$ and the probability that Customs detects evasion changes to $(\gamma+\delta)=1$. The Importer then decides whether or not to evade given the choice of the Ministry of Finance.

The choices of the actors outlined above are illustrated in the game tree in Figure 2. The primary purpose of the model is to investigate under what institutional conditions the implementation of a PSI contract by the Ministry of Finance will lead to a successful ex-post reconciliation. Sub-game perfect equilibrium pay-offs corresponding to effective use of PSI are (1) and (2).

Figure 2: The Game

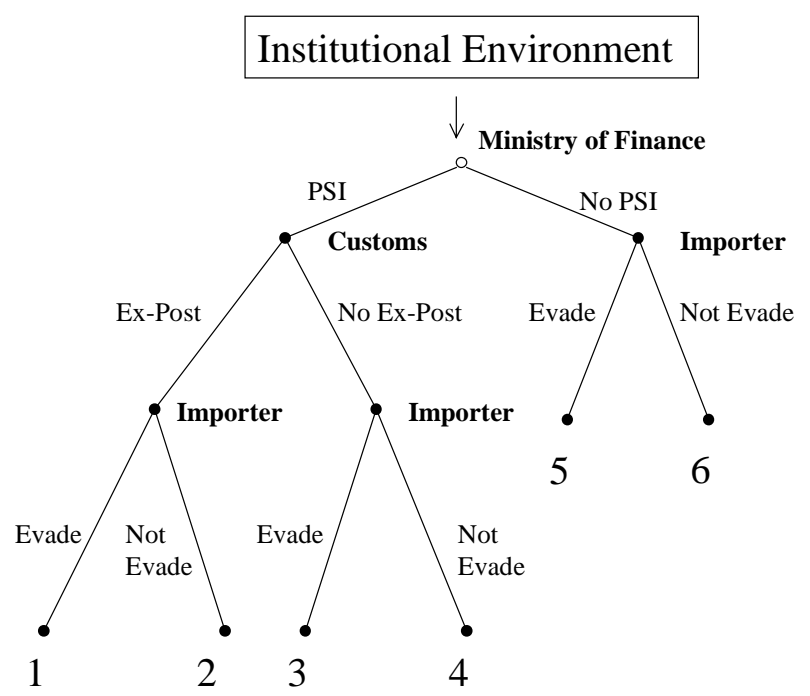

In what follows, we proceed by backwards induction. We begin by looking at the decision of the Importer as to whether or not to evade in the absence of a PSI contract. We will then look at the decision Customs faces as to engaging in ex-post reconciliation, given the choice of the Importer. Then, we will investigate the decision of the Ministry of Finance given the other player's choices, as to whether or not to implement PSI.

\footnotetext{
${ }^{23}$ It is assumed that if Customs provides the information it does so truthfully.
} 
The evasion decision of the Importer depends upon whether or not Customs is corrupt. If Customs is corruptible and equation (1) holds, then the Importer will evade if:

$$
V_{e}-\gamma\left(b+\pi P_{a}^{I}\right)-V_{n e}>0
$$

Equation (3) is presented graphically in $(\gamma, h)$ space in Figure $3 .^{24}$ Given the other exogenously determined institutional variables, we can represent under what combination of $\gamma$ and $h$ the Importer will choose to evade or not evade. We choose to vary $\gamma$, the probability that Customs catches evasion in the absence of the information provided by ex-post reconciliation, because the more revenues that Customs receives, through either corruption, or, rewards for catching evasion, the less willing it will be to implement a PSI contract. By reducing evasion, successful use of ex-post reconciliation would, in effect be eliminating these sources of revenue for Customs. We look at the value of $h$ because it indicates the rate of incentive pay received by Customs. The higher the value of $h$, the more likely it is that Customs will be willing to raise tax revenues by using ex-post reconciliation. We will see that the success of PSI will be highly dependant upon the ability of the Ministry of Finance to institute an institutional regime with positive incentive pay.

Figure 3: Importer's Choice

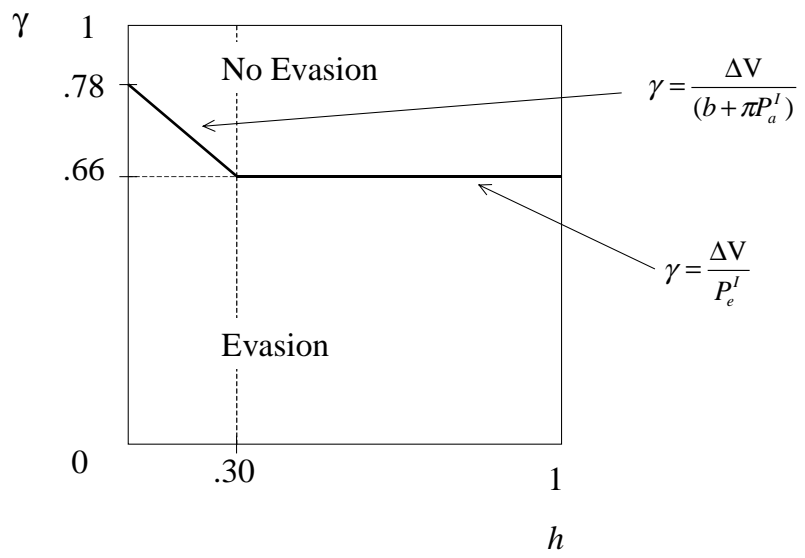

In Figure 3, given our choices for parameter values, as $h$ increases, eventually we reach a point where Equation (1) holds with equality and Customs is no longer corruptible. When this happens, the Importer faces a new set of trade-offs. In the noncorruptible regime, the Importer would attempt to evade taxes so long as:

${ }^{24}$ The parameter values used are: $P_{e}^{I}=150, \Delta V=\Delta t=100, r=75, P_{a}^{I}=P_{a}^{C}=150, \pi=.1, k=.5$ 


$$
\Delta V-\gamma P_{e}^{I}>0
$$

That is, as long as the net benefits from evasion are greater than the expected costs of getting caught by Customs and having to pay a fine, the Importer will evade. Given the way we have set up the problem, as the variable $h$ increases in equation (1) as Customs is moving towards no longer being corrupt, at the point where equation (1) holds with equality, then, equation (3) reduces to equation (4). That is:

$$
\operatorname{Lim}_{r+h \Delta t \rightarrow P_{e}^{I}-\pi\left(P_{a}^{I}+P_{a}^{C}\right)}\left\{\Delta V-\gamma\left(b+\pi P_{a}^{I}\right)\right\}=\Delta V-\gamma P_{e}^{I}
$$

This means, that as $h$ increases in equation (1) eventually, a point is reached at which Customs is no longer corrupt (that is, willing to take a bribe), the line in Figure 3 marking the cut-off between evasion and no evasion becomes flat at the value where Customs is no longer corruptible, represented by, $\gamma=\frac{\Delta V}{P_{e}^{I}}$. Thus, in Figure 3 every point above the line represents values for $\gamma$ and $h$ for which the Importer will not evade and points below the line indicate parameter values for which the Importer will attempt to evade.

The cut-off line in Figure 3 will shift as we alter the values of the parameters. Thus, for example, if $k$, the bargaining power of Customs over the Importer, was to increase, then this would rotate the line segment between $0 \leq h \leq .3$ down. If $\Delta V$, the benefit to evasion accruing to the Importer, was to increase, this would shift the entire cut-off line up and, as one would expect, increase the range of parameters over which the Importer would evade.

Having characterized the decision of the Importer given the institutional parameter values in the absence of PSI, we now investigate the decision of Customs as to whether or not to implement an ex-post reconciliation given the choice of the Importer. In the absence of PSI and given our choices of parameter values, the Customs Agent will be corrupt for values of $h$ less than .3. If a PSI contract is introduced and an ex-post reconciliation is undertaken then what, in effect, is happening is that the probability that Customs catches evasion increases to 1 and the probability that the Ministry of Finance identifies corruption on the part of Customs increases to 1. It follows, that if the Ministry of Finance could force Customs to always engage in ex-post reconciliation, then both evasion and corruption would be eliminated. However, simply requiring an ex-post reconciliation in a contract will not necessarily ensure its occurrence. Since the Ministry of Finance cannot force customs to use the information coming from PSI, Customs will use it according to its best interests. The question is, in the game that we describe in Figure 2, "Under what conditions will it be a sub-game perfect equilibrium for Customs to engage in ex-post reconciliation when the Ministry of Finance chooses to implement a PSI contract?"

Given that a PSI contract is in place, Customs will engage in ex-post reconciliation so long as their payoff from doing so is greater than in its absence. If 
Equation (1) holds and Customs is corrupt, this means that they will engage in ex-post reconciliation so long as:

$$
h t_{n e}>\gamma\left(b-\pi P_{a}^{C}\right)+h t_{e}
$$

Likewise, if Customs is not corrupt, then they will engage in ex-post reconciliation so long as:

$$
h t_{n e}>\gamma(r+h \Delta t)+h t_{e}
$$

In Figure 4 we construct the cut-off line between engaging in ex-post reconciliation (below the line) and not engaging in ex-post reconciliation (above the line) given different choices for the parameter values $\gamma$ and $h$.

Figure 4: Customs Agent's Choice

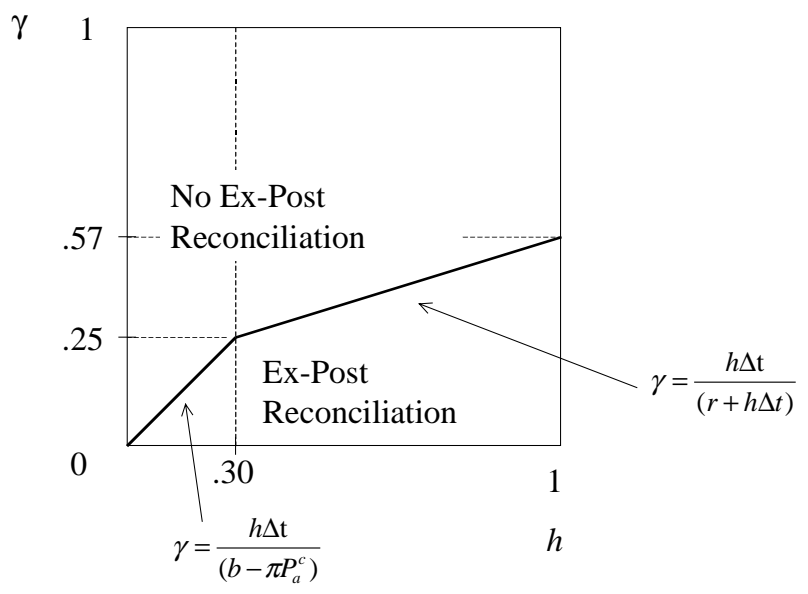

In a manner analogous to the Importer's problem, as $h$ increases and we move from a regime in which Customs is corrupt to one in which it is not, equations (5) and (6) are equal in the limit. That is:

$$
\operatorname{Lim}_{r+h P_{e}^{l} \rightarrow P_{e}^{I}-\pi\left(P_{a}^{I}+P_{a}^{c}\right)}\left\{h \Delta t-\gamma\left(b-\pi P_{a}^{c}\right)\right\}=h \Delta t-\gamma(r+h \Delta t)
$$

As with Figure 3, when we alter the values of parameters other than $\gamma$ or $h$ the cut-off line will shift accordingly. Thus, if $\Delta t$, the value of eliminating evasion in terms of tax revenues, were to increase, then the slopes of both line segments in Figure 4 would increase by the same amount. The intuition being, that as the value of the Customs Agents share of tax revenues increases, the benefits from ex-post reconciliation also increases. Similarly, if the reward to catching evasion were to increase, this would cause the part of the cut-off line to the right of $h=.3$ to decrease in slope. The intuition behind 
this change being that, if the reward increase, the opportunity cost of engaging in ex-post reconciliation and eliminating evasion altogether also increases. A similar analysis could be done for the other parameter values.

We are now able to describe the behavior of Customs and the Importer under any given choices for the parameter values. Figure 5 combines the cut-off line between evasion and no evasion for the Importer in Figure 3 with that of Custom's cut-off line for ex-post reconciliation in Figure 4.

Figure 5: The Combined Choice

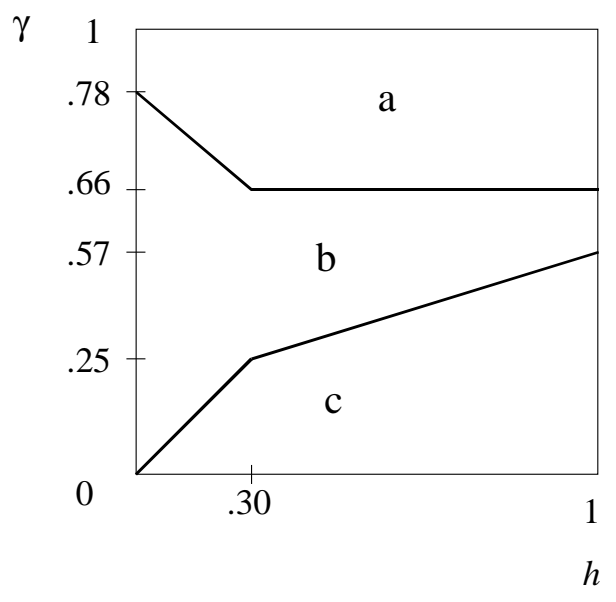

Using the Figure we can completely characterize the effect that the Ministry of Finance's implementing a PSI contract will have under differing institutional regimes. In particular, we can identify three different regions in Figure 5 which correspond to different subgame perfect equilibria resulting from the implementation of a PSI contract. If the values of $\gamma$ and $h$ are such that we are at a point like (a), then there will be no evasion or corruption regardless of whether or not a PSI contract is in place. In our game tree in Figure 1, region (a) would correspond to a sub-game perfect equilibria of (4) if the Ministry of Finance chooses to implement PSI, or, a sub-game perfect equilibria of (6) if it chooses not to implement. Of course, this is a trivial case since there would be no reason to introduce reforms if there were no problem in the first place. Furthermore, introducing PSI would just add an unneeded cost to collecting taxes. Thus, under an institutional regime corresponding to region (a) PSI would not be implemented by the Ministry of Finance and should not be encouraged, or, required from the outside.

The second region is one in which the values of $\gamma$ and $h$ are such that we are at a point like (b), above the region where ex-post reconciliation takes place and below the region in which there is no evasion. To the left of $h=.30$ corruption and evasion persist even if the PSI contract is implemented. To the right of $h=.30$ corruption has already been eliminated due to the large value of share pay, however, there is still not enough of 
an incentive for the Customs Agent to engage in ex-post reconciliation. In effect, what's happening is that Customs is getting more in rewards from reporting evasion than he would in share-pay by eliminating evasion altogether. Thus, if the Ministry of Finance chooses to not implement PSI we end up at pay-off (5) in Figure 1 and tax revenues will be equal to $(1-h) t_{e}+\pi\left(P_{a}^{I}+P_{a}^{C}\right)$. However, if the Ministry of Finance chooses, or is forced, to implement a PSI contract under these circumstances, then we end up at pay-off (3) in Figure 1 and tax revenues will be less by the cost of paying for the services of the PSI company, $c_{p}$. It follows, that attempting to implement a PSI contract in region (b) would be pareto inferior to simply accepting the status quo.

The last region, (c) corresponds to an institutional regime in which PSI may actually be effective, in the sense that it will be a sub-game perfect equilibrium for Customs to carry out ex-post reconciliation. In the region to the left of $h=.3$, Customs is corrupt before the introduction of the PSI contract and accepting bribes, but after its introduction Customs gets enough in share pay that it carries out ex-post reconciliation and corruption and evasion disappear. Similarly, to the right of the $h=.3$ customs is not corrupt before the introduction of the PSI contract, but evasion is positive. After the introduction of PSI, evasion disappears due to the successful use of ex-post reconciliation. These two regions correspond to either payoff (2) or (5) in Figure 1 depending upon whether or not the Ministry of Finance chooses to employ a PSI company. If PSI is implemented, then tax revenues accruing to the Ministry of Finance will be equal to $\left[(1-h) t_{n e}-c_{p}\right]$. If PSI is not used, then the Ministry of Finance gets, $\left[(1-h) t_{e}+\pi\left(P_{a}^{I}+P_{a}^{C}\right)\right]$. Thus, it will be a sub-game perfect equilibrium in Figure 1 for the Ministry of Finance to use PSI so long as:

$$
\Delta t>\frac{c_{p}+\pi\left(P_{a}^{I}+P_{a}^{C}\right)}{(1-h)}
$$

Basically, in order for PSI to be implemented in region (c), the gain in tax revenues accruing to the Ministry of Finance from using PSI must be greater than the cost of the PSI company plus foregone rewards from catching corruption.

\section{Section 3: Policy Recommendations}

Using Figure 5 and the analysis which proceeded it, we can now proceed draw some policy recommendations concerning under what institutional settings PSI will be successful. At the end of section one we identified two of the most prevalent assumptions concerning PSI in the current literature. They were, (1) That PSI should be implemented in "weak" institutional regimes and, (2) That successful ex-post reconciliation is absolutely vital to the success of the PSI contract. We can now use our model to form a more specific definition of what might be meant by "weak" institutions, and, to identify if such institutions are compatible with successful ex-post reconciliation. 
Let's first consider what might be meant by "weak" institutions. There seem to be two possible interpretations in the literature. In the first, "weak" institutions refers to the ability of the Ministry of Finance to implement a comprehensive civil service reform. Such reforms would include altering parameters, other than whether or not to implement PSI, in order to eliminate corruption or evasion. Furthermore, typically, in the vast majority of the situations in which the Ministry of Finance is weak in this sense, Customs Agents are compensated with only wages and, perhaps, some rewards for reporting evasion. There is almost never incentive pay of the form implied by an $h$ greater than zero.

Our model gives a very strong result for cases in which the Ministry of Finance is weak in this first sense. In particular, if we assume that $h=0$, looking at Figure 5, we see that it will never be optimal for the Ministry of Finance to implement a PSI contract. ${ }^{25}$ Either Customs will choose not to engage in ex-post reconciliation and remain corrupt (when $\gamma<.78$ ), or, there will be no evasion in the first place (when $\gamma>.78$. In either case PSI should not be used.

This first situation probably corresponds closely to African countries, such as Tanzania, Mali, and Zambia where Low found that ex-post reconciliation was not being undertaken. Even if ex-post reconciliation is included as a clause in the PSI contract between the Ministry of Finance and Customs, it is unlikely that it actually will be fulfilled. This is particularly true of regimes in which Customs is relatively independent of the Ministry of Finance. There must be accompanying civil service reforms in support of the PSI contract. In particular, there needs to be some incentive, whether it be positive share pay, or, negative penalties, which work on the margin to change the incentives of Customs Agents so that they engage in ex-post reconciliation.

There is a second possible interpretation of "weak" that corresponds to Customs having a great deal of power in the absence of PSI. This would correspond to a high $\gamma$ or $k$ for Customs meaning that it is benefiting a great deal from corruption or rewards for catching evasion in the absence of PSI. When $\gamma$ is large, then Customs is getting a larger bribe if it is corrupt, and a larger reward if it is not corrupt. Likewise, if $k$ is close to 1 , then Customs can extract a very large bribe from the Importer. In either case, the opportunity cost for Customs to engage in ex-post reconciliation is high. In Figure 5, such a situation of "weak" authority would put us at a point such as (b). Thought of in a slightly different way, the more that institutions are "weak" in this second sense, the greater have to be the accompanying reforms (such as implementing higher share-pay) which accompany the introduction of the PSI contract.

One may wish to conclude that a corollary to the last statement concerning weak institutions would be that when Customs does not posses a great deal of power (e.g. when $\gamma$ or $k$ are close to zero), then introducing PSI makes a great deal of sense. This is true up to a point. However, if we consider the fact that when Customs is not very powerful in

\footnotetext{
${ }^{25}$ This result is not dependant upon our choice of parameters.
} 
the sense of having low values for $\gamma$ or $k$, then it is probably reasonable to assume that it will also tend to not be in control of its own borders. Then, engaging in ex-post reconciliation would not cause evasion to cease, it would simply cause Importers to avoid PSI and Customs Inspectors altogether and smuggle their goods across the border. In terms of our game in which Customs chooses whether or not to engage in ex-post reconciliation, this shift to smuggling, would have the effect of eliminating at least some of the increase in revenues which the PSI contract is supposed to bring them. This, in turn would cause Customs to maintain the status quo and not engage in ex-post reconciliation. This appears to be the situation which existed in Mozambique where Customs had only tenuous control over its western borders.

It seems then that the current consensus that PSI should be used as a deterrent to corruption and evasion in situations where "weak" institutions prevent full-fledged reforms is flawed. In particular, as we have shown, under a fairly wide interpretation of "weak" institutions, the introduction of PSI will not be consistent with Customs undertaking ex-post reconciliation. At the very least, in order for PSI to succeed, its introduction must be accompanied by reforms which create positive incentives for the implementation of ex-post reconciliation, or, in lieu of that, there must be credible punishments for not supporting the terms of the contract. ${ }^{26}$ Given the fact that these are precisely the conditions which are often missing under weak institutional regimes, the scope for the successful use of PSI, alone, to deter corruption and evasion is limited.

There are obviously situations in which PSI has been extremely effective. The case of the Philippines being one of them. There PSI was introduced in conjunction with extensive reforms, one of which, allowed Importers to completely bypass Customs and pay tariffs based on the PSI company's findings directly to the bank in the Philippines by means of electronic transfer. In effect this was a deal between the Ministry of Finance and the Importers by which both gained, since the Ministry of Finance received tax revenues and the Importers managed to avoid extortion by the Customs Agency. We did not include extortion of Importers by Customs as a possibility in our model, but it does seem to be one of the situations in which PSI could succeed.

Another implication of the model is that PSI could work very well in conjunction with high share pay for Customs Agents. Typically, the problem with paying tax collectors with high shares is that they become over-zealous and extort money from the tax payers. The government gets its money, however, the taxpayer ends up paying too much due to over-taxation. The result can be worse for society than just leaving the tax collector with low-powered incentives. The introduction of PSI in conjunction with high share pay would have the possibility of overcoming many of the transaction costs associated with high share pay. In particular, if the PSI company is sending a copy of the Report of Findings to the Ministry of Finance as well as the Customs Agent, then the costs of determining when over-taxation is taking place are relatively low. It is in the

\footnotetext{
${ }^{26}$ Note that, according to the model, credible large punishments may reduce the amount of evasion and corruption, however, they will not create any incentive for Customs to engage in ex-post reconciliation. Only share-pay will do this.
} 
interests of the Importer to report over-taxation, and the Ministry of Finance has the information they need to confirm that the claims of the Importer are valid. Furthermore, the introduction of high share pay along with the information provided by PSI to Customs results very easily in the elimination of evasion and corruption opportunities from underinvoicing. The two contractual forms of high share pay and PSI dovetail extremely well, minimizing each others transaction costs. Nonetheless, this last observation remains purely academic if it is not within the purview of the Ministry of Finance to implement reforms which complement the introduction of PSI.

\section{Conclusion}

Development agencies tend to consider PSI as a second-best alternative to comprehensive customs reform. As such, it is often claimed that it should be used in situations in which a country lacks the institutional capacity or will-power to engage in full-fledged reform. However, it also claimed in most studies that successful ex-post reconciliation should be a pre-requisite of a well functioning PSI contract. The primary contribution of this paper has been to show that these two guides to policy are, in many cases, contradictory. If a country does not posses the institutional capacity to engage in reforms other than PSI to eliminate corruption and evasion, then PSI is not going to do it on it's own. Furthermore, it is precisely in situations in which countries have weak institutions that the requirements for a credible commitment to engage in ex-post reconciliation by both customs and the ministry of finance are missing.

One implication of these findings is that, perhaps, PSI should be thought of less in terms as a second best solution for customs reform in countries with poorly functioning customs services, but rather in terms of a cost-effective complement to reforms in "intermediate" countries in which there already exists a relatively well functioning customs service. PSI could contribute in these "intermediate" cases by reducing the costs of catching evasion and, thereby, making it easier for the ministry of finance to maintain separate reforms designed to eliminate corruption between customs and importers. What is certain, is that in countries in which the customs service is relatively powerful (in the sense of being highly independent and in control of the country's borders) and in which the government does not have the institutional capacity to make reforms complementary to the introduction of PSI, then simply introducing a PSI contract will almost certainly add an extra burden to the country's public finances rather providing the panacea which is hoped for. 


\section{Notational Appendix}

\begin{tabular}{|c|c|}
\hline$V_{n e}$ & $\begin{array}{l}\text { Value of imports without } \\
\text { evasion }\end{array}$ \\
\hline$V_{e}$ & $\begin{array}{l}\text { Value of imports with } \\
\text { evasion }\end{array}$ \\
\hline$t_{n e}$ & $\begin{array}{l}\text { Tax revenues without } \\
\text { evasion }\end{array}$ \\
\hline$t_{e}$ & Tax revenues with evasion \\
\hline$\Delta V$ & $V_{e}-V_{n e}$ \\
\hline$\Delta t$ & $t_{n e}-t_{e}$ \\
\hline$c_{m}$ & $\begin{array}{l}\text { Fixed cost faced by Customs } \\
\text { for monitoring imports }\end{array}$ \\
\hline$\gamma$ & $\begin{array}{l}\text { Probability that Customs } \\
\text { catches evasion }\end{array}$ \\
\hline$P_{e}^{I}$ & $\begin{array}{l}\text { Penalty paid by importer for } \\
\text { evasion if reported by } \\
\text { Customs }\end{array}$ \\
\hline$r$ & $\begin{array}{l}\text { Reward to Customs if they } \\
\text { report evasion }\end{array}$ \\
\hline$\pi$ & $\begin{array}{l}\text { Probability that Ministry of } \\
\text { Finance detects corruption } \\
\text { between Customs and } \\
\text { Importer }\end{array}$ \\
\hline$P_{a}^{C}$ & $\begin{array}{l}\text { Fine paid by Customs if } \\
\text { found corrupt by Ministry of } \\
\text { Finance }\end{array}$ \\
\hline$P_{a}^{I}$ & $\begin{array}{l}\text { Fine paid by the Importer if } \\
\text { found corrupt by the } \\
\text { Ministry of Finance }\end{array}$ \\
\hline$h$ & $\begin{array}{l}\text { Percentage of tax revenues } \\
\text { paid as share pay to Customs }\end{array}$ \\
\hline$k$ & $\begin{array}{l}\text { Bargaining power of } \\
\text { Customs vis a vis the } \\
\text { Importer }\end{array}$ \\
\hline$c_{P}$ & $\begin{array}{l}\text { Cost faced by Ministry of } \\
\text { Finance of using PSI }\end{array}$ \\
\hline$\delta$ & $(1-\gamma)$ \\
\hline$b$ & $\begin{array}{l}\text { Value of the bribe paid by } \\
\text { the Importer to Customs }\end{array}$ \\
\hline
\end{tabular}

